\title{
Barriers to Downward Carbon Emission: Exploring Sustainable Consumption in Face of the Glass Floor
}

\author{
Dr Hélène Cherrier ${ }^{1}$ \\ Griffith University, Department of Marketing, Nathan, Brisbane QLD 4111. \\ h.cherrier@griffith.edu.au
}

Mathilde Szuba

University of Paris 1, Panthéon-Sorbonne, France. Mathilde.Szuba@malix.univ-paris1.fr

Dr Nil Ozcaglar-Toulouse

\author{
Univ Lille Nord de France Lille School of Management Research Center (LSMRC), \\ France. \\ nil.toulouse@univ-lille2.fr
}

Dr Hélène Cherrier (PhD University of Arkansas) is a Senior Lecturer at Griffith University, Brisbane, Australia. Dr. Cherrier's research interests embrace radical changes in consumption lifestyles, social and environmental activism, appropriation and reconfiguration of consumer meanings, symbols, and usage, identity politics, and the role of disposal in identity construction. Dr. Cherrier has published her work in several conference proceedings and in refereed academic journals including the Journal of Business Research, the Journal of Qualitative Market Research, Marketing Education Review, Advances in Consumer Research, the Journal of Research for Consumers, Consumption, Markets \& Culture, the Journal of Consumer Behavior, the European Journal of Marketing, the Journal of Marketing Management, the International Journal of Consumer Studies, World Management Review, and contributed to Harrison, Newholm, and Shaw's edited book: "The ethical consumer." She also co-edited a book on the theories and practices of simple living.

Mathilde Szuba is a PhD student in Sociology at the University of Paris 1, Panthéon-Sorbonne. Her supervisor is Professor Alain Gras from the CETCOPRA: Technology, Knowledge and Practices Research Centre. She received a research grant from the French Agency for the Environment and Energy Management (ADEME). Her research interests focus on energy and climate policies, voluntary and mandatory energy consumption contraction, personal carbon quotas, energy sufficiency and the cultural meanings of energy consumption. Her work has recently been published in Sociologies Pratiques, Presses de Science Po (2010) and in Séverine Frère et Helga-Jane Scarwell (eds), Ecofiscalité et transport durable: entre prime et taxe?, Septentrion, 2011. She is part of the editorial board for Entropia, and Développement Durable et Territoires. She is currently involved in "Sobriétés", a research program on sufficiency.

Dr Nil Ozcaglar-Toulouse is an Assistant Professor of Marketing at Univ Lille North of France and affiliated researcher at Skema. She primarily carries out research in the field of consumption, including analyzing consumer ethics, immigration, sustainable development or promising niche markets such as fair trade. Her work has been published in Décisions Marketing, Recherche et Applications Marketing, Journal of Business Research, Journal of Macromarketing, Journal of Business Ethics, International Journal of Consumer Studies, Advances in Consumer Research, etc. She is also co-author of several books. She has also presented her research findings at international marketing conferences (ACR, EACR, CCT, AFM, AM...). Nil is a co-founder of FairNESS (Network on Exchanges in Social Sciences) and a member of the Association of Consumer Research and French Marketing Association.

\footnotetext{
${ }^{1}$ Corresponding author
} 


\section{Barriers to Downward Carbon Emission: Exploring Sustainable Consumption in Face of the Glass Floor}

\footnotetext{
Abstract: The present study explores the constraining forces to reducing greenhouse-gas emissions (GHG) via alternative and/or reduced consumption. The analysis of introspection, netnography, ethnographic work, and eighteen interviews demonstrates that needs are not innate human requirements and that consumers are not free and autonomous agents able to incorporate reduce or alternative consumption within their lifestyles. Specifically, our analysis shows the existence of barriers to downward carbon emission. These barriers, that we combined under the concept of the glass floor, represent socio-cultural standards preventing our informants from achieving their goal of reducing carbon footprint. Our findings are presented around two main themes: the social construction of needs and the social imaginary.
}

Keywords: Sustainable Consumption, Sustainability, Social Imaginary, Green Marketing, Glass Floor. 


\section{Introduction}

In line with the Brundtland terminology of sustainable development (see Brundtland Commission, 1987, p.1), environmentally and socially responsible consumption, i.e., sustainable consumption, represents consuming in a manner that meets the needs of present generations without compromising the future ones (Heiskanen \& Pantzar, 1997). It calls for consumers to "consider ecological and social criteria in the purchase, use and post-use of products (Belz \& Peattie, 2009, p. 33). Within the green marketing field, sustainable consumption has been discussed in terms of "alternative consumption" as well as "reduced consumption" (Belz \& Peattie, 2009; Fisk, 1973; Grant, 2007). In promoting alternative consumption, green marketers discuss sustainable consumption in terms of developing efficient supply, design, and production systems via technological innovation and offering green products targeted to "green consumers" or "eco-consumers" (Dahlstrom, 2011). In addition to alternative consumption (getting more output out of less input), some green marketers endorse reduced consumption and sufficiency (having enough and acting with what we have) as a sustainable consumption practice. For example, Ottman supports "energy conservation associated with using product" and encourages "consumer to use only what is needed, and consciously reduce waste (Ottman, 2011, p. 154). Similarly, Grant (2007) identifies reduced consumption and consumption abstention as sustainable consumption practices.

Although distinctive in approach and practice, alternative and reduced consumption strategies both distribute consumers along the spectrum of autonomy, rationality and need satisfaction. From the decision to purchase eco-friendly products to the participation in anti- 
consumerist ethics, individuals are called to reflect on their idiosyncratic aspirations and socio-environmental concerns and to rationally orient their lifestyles accordingly. For example, alternative consumption practices satisfy consumers' needs for social esteem, identity and political participation (Connolly, 2003; Heiskanen \& Pantzar, 1997; Kilbourne, McDonald, \& Prothero, 1997; Shaw, Newholm, \& Dickinson, 2006) and reduced consumption satisfies consumers' needs for self-fulfillment, happiness, and good-life (Elgin, 1981; Schumacher, 1974). Importantly, these approaches rest on the neo-liberal assumption that consumers are autonomous, free to choose alternative and/or reduced consumption to satisfy their self-interested needs and respond to their socio-environmental concerns (Autio, Heiskanen, \& Heinonen, 2009; Heiskanen, 2005). In this study, we argue that needs are not innate human requirements and that consumers are not free and autonomous agents able to incorporate reduce or alternative consumption into their lifestyles. Specifically, we show that accepting a neo-liberal approach to consumers as autonomous free agents in the domain of green marketing underestimates the powerful constraining forces embedded in the dominant system of codification, symbolic representations and social norms. In the following discussion, we review the literature on alternative consumption and reduced consumption with an emphasis on the modernist axiom of autonomy, free choice and need satisfaction. The analysis of introspection, netnography, ethnographic data and eighteen existential interviews collected from individuals who, through practices of alternative and/or reduced consumption, try to reduce their carbon footprint, unveils the constraining social and cultural forces to sustainable consumption practices. Our findings are presented around two main themes: the social construction of needs and the social imaginary. Our discussion brings forward issues of the glass floor and the 'decolonization of the social imaginary' to the green marketing debates. 


\section{Green Marketing and Sustainable Consumption: Alternative Consumption}

Consumer researchers often equate green marketing to "the marketing of products that are presumed to be environmentally safe" (American Marketing Association). Consequently, much attention in the green marketing literature has been placed on identifying 'green consumers' or 'eco-consumers', establishing relevant segmentation strategies, and developing eco-performance as a competitive advantage factor to serve the green consumer (Belz \& Peattie, 2009; Dahlstrom, 2011). This approach to green marketing is micro-situated and positions alternative consumption as an environmentally and socially responsible consumption; i.e. sustainable consumption.

Within this stream of study, alternative consumption refers to a cut back in resource consumption per consumption unit (Fuchs \& Lorek, 2005; Reisch, 2001; Sanne, 2000). The thrust of this perspective is questioning the quality, rather than the quantity, of consumption patterns in affluent societies. Proponents to alternative consumption argue that we 'misconsume' and that consumers need to switch their consumption lifestyle to greener and more environmentally conscious consumption practices using eco-efficient product and services (Ottman, 1993). For the switch to occur, two components need to exist. First, improvements in production processes, eco-friendly designs and environmental product innovations provide alternative eco-efficient means of consuming. This development is situated within the existing marketplace and rest on prevalent modernist notions of efficiency, measurement of ecological impact, technological rationality and scientific objectivity (Kilbourne, 1998).

A second element of alternative consumption is the existence of rational and environmentally aware consumers who make decisions based on their deep values (Ottman, 1993). These consumers, named “environmentally conscious consumers" (Ottman, 1993) or “green consumers" (Elkington, Hailes, \& Makower, 1990; Tanner \& Kast, 2003), are 
environmentally informed, care for the environment and consume accordingly (Ottman, 1993). Green consumers rationally respond to their environmental concerns (Ottman, 1993) and use their purchasing power to construct green identities, uplift their self-esteem, or vote for socio-political changes (Connolly, 2003; Heiskanen \& Pantzar, 1997; Kilbourne et al., 1997; Moisander \& Pesonen, 2002; Nava, 1991; Shaw et al., 2006). Particular to this perspective is the emphasis on consumer power to bring about social change by considering the consequences of their purchase and usage on the environment and businesses. As Nava notes, people are 'able through their shopping to register political support or opposition' (1991, p. 168). Here, the motivations for alternative consumption incorporate needs for functionality of the object/service as well as needs for the meanings of consumption and needs for the values the meaning provides (Connolly, 2003).

The green claim in this spirit is that consumers are rational, goal-oriented individuals, attempting to satisfy their personal, social and ecological needs via marketplace offerings. This perspective follows the prevalent ideology of progress and the marketplace in general (Belz \& Peattie, 2009; Kilbourne et al., 1997), and is essentially based on the neo-liberal view that consumers are free and autonomous agents aiming at satisfying their needs. In other word, alternative consumption is positioned along the pervasive model of individual choice and agency; and consumers are empowered to switch their consumption patterns if that is what they choose.

Although the model of rational action, individual choice, autonomy and agency is still prevalent in green marketing textbook (Ottman, 1993), many authors argue that the assumption of "rationalization of lifestyles" (Hobson, 2002), "individualistic conceptions of subjectivity and human agency" (Autio et al., 2009, p. 42), and autonomous agent (Heiskanen, 2005) is problematic as it fails to consider the historical, political and social constraining forces of daily lives. This discrepancy has prompted authors to call for 
conceptualization of sustainable consumption, lifestyle and behavior outside of the dominant model of rational action and free choice (Black \& Cherrier, 2010; Cherrier \& Murray, 2007; Shove, 2005).

\section{Green Marketing and Sustainable Consumption: Reduced ConsumptionAccording} to recent literature, green marketing is shifting toward incorporating a macro-perspective by questioning the marketing ethos and consumerism (Kilbourne, 1998; Kilbourne \& Beckmann, 1998). For example, Grant (2007) defines the new green marketing perspective by combining 'working with' to working "against consumerism as we know it today" (Grant, 2007, p. IX). The new green marketing promotes conservation, sharing, reusing, recycling, slowing down, and treasuring as well as a reduction of consumption and even an abstention from consumption (Grant, 2007). Compared to alternative consumption, which supports that continued economic growth is compatible with environmental preservation (Fisk, 1973), reduced consumption includes rethinking the predominant 'cycle of consumption' (Schor, 1999) and unlimited progress (Durning, 1992). The thrust of this perspective is questioning the quantity of our consumption patterns. Proponents to reducing consumption claim that consumers need to re-consider their needs and reflect on the relation between affluent consumption and life fulfilment. The concern is explicit in Arrow et al. manuscript entitled: “Are we consuming too much?" (Arrow et al., 2004) and in Schor's book called "Why we want what we don't need?" (Schor, 1999).

In terms of the motivations to reduced consumption practices, studies show a combination of socio-environmental as well as self-interested concerns. For example, Sandikci and Ekici (2009, p. 3) state:

"consumer may refrain from using a particular product or brand as a reflection of their desire to influence business practices and promote what is good for the society overall, or as part of their desire to avoid social groups, roles, and identities that represent the negative self". 
Another support for this perspective is found in Iyer and Muncy (2009) distinction between societal anti-consumers and personal anti-consumers. While the former avoid practices of consumption for the benefit of society or the planet in general, the latter is dominantly concerned with being a healthy and happy self. From this perspective, reducing consumption is good for the environment and also good for the individuals. It is good for the environment as reduced consumption leads to less production and waste and it is good for consumers as minimizing consumption leads to financial freedom, less stress, personal integrity, and good life (Black \& Cherrier, 2010; Cherrier \& Murray, 2007; Schor, 1998, 1999, 2000). Here, consumers' personal interests constructed around socio-environmental concerns lead them to voluntarily reduce the quantity of their consumption by purchasing less, using less and wasting less.

The model of reduced consumption is based on the consumers' interpretation of their environmental concerns and personal interests. This approach inevitably calls consumers to reflect and re-evaluate their personal needs in conjunction with their environmental concerns and self-interests. The task is to differentiate between paradigmatic/superfluous/false/nonsustainable needs versus focal/necessary/real/sustainable needs. For example, Reisch notes that individuals will change their lifestyle once they "learn to identify those goods whose consumption adds little or nothing to welfare" (Reisch, 2001, p. 369) and Borgmann urges consumers to break the spell of paradigmatic consumption in order to "clear a central space in our lives for the engagement with focal things and practices" (Borgmann, 2000, p. 422). Ultimately, consumers who can identify their true needs will reduce their paradigmatic (Borgmann, 2000), superfluous (Schor, 1999) or non-sustainable (Pierce, 2000) consumption accordingly and "be happier in the process" (Pierce, 2000). 
However, following Dolan's argument, differentiating between types of needs raises questions on how to identify the 'real' from the 'false' needs and who can identify them (Dolan, 2002). Furthermore, according to the social constructivists, needs are not absolute and mere representations of individual preferences (Slater, 1997). Rather, consumer needs are socially and culturally constructed. They emerge from evolving historical ways of life; constantly framed, constrained and enabled by social interactions. As Dolan notes, "needs are mediated by the prevailing symbolic order which is part and parcel of the cultural system" (2002, p. 175). The social construction of needs creates cultural norms of how people should live and what needs have to be satisfied within society. Individual power to control and act upon their needs is consequently dependent on the historical, political and social condition of daily life. Thus, needs should only be conceptualized as part of the cultural system.

At its best, this brief review of the literature shows the emergence of a critical voice in discussions of alternative and reduced consumption. Broadly, this critical lens in the green marketing debate challenges the neo-liberal perspective per se by arguing for a reconceptualization of alternative and reduced consumption constrained by social and cultural forces, rather than located in the autonomous free agent aiming at satisfying its needs. Following this critical perspective, the present study explores the constraining forces to reducing greenhouse-gas emissions (GHG) via alternative and/or reduced consumption. The analysis reveals the existence of a minimum level of socially required GHG, which we explain using the analogy of a 'glass floor'. Under this threshold, an individual transgresses the socially dominant rules of the consumer society and faces risk of social exclusion and marginalization. Our analysis shows two main strata to the glass floor: the social construction of needs and the social imaginary. Each stratum is discussed in the result section. 


\section{The Study}

The study considers data collected during 2009 and 2010 from individuals who consciously aim at lowering their carbon footprint. These individuals are either selfproclaimed objecteurs de croissance living in France or belong to the Crag movement located in the United Kingdom. The choice of these groups is based on their commitment to lower carbon emission. According to the 2008 census organized by the CRAG network, a

CRAGger decreases its carbon footprint by $36 \%$ in the first year of participation in a CRAG and an Objecteur de Croissance, whilst not taking a quantitative approach on their carbon footprint, consumes significantly less than what an average individual of the same social status consumes per year (Howell 2009; Latouche 2005). Personal contacts and snowbowling technique offered access to each informant and field work used for this study.

First, the objecteurs de croissance ("growth objectors", a play on conscientious objector / objecteur de conscience in French) were located in France and identify with degrowth economics. This movement first appeared in France around the year 2003 and is based, in particular, on the writings of the French economist Serge Latouche. He argues that seeking increased GDP and the tendency to assess everything in terms of economic growth is leading societies to their downfall. The movement aims to break with the ideology of growth (Latouche, 2005). Its environmental perspective leads to a strong desire to reduce carbon footprints (Boutaud \& Gondran, 2009).

Second, the CRAGgers, members of Carbon Rationing Action Groups, were located in the UK. A CRAG is a group of around a dozen individuals who meet on a regular basis to calculate their GHG emissions together, set reduction goals and exchange tips on how to reach them. Symbolic financial penalties are sometimes meted out if members exceed set targets. In 2008, while the average carbon footprint in the UK was 5.4 tons per capita per 
year, the average goal of CRAG members was to stay under 3.8 tons. Over the long term, they hope to reach a sustainable level of 0.5 tons.

The choice of these two groups is justified by their varied approaches to lowering carbon emission. Whilst the objecteurs de croissance are against the ideology of progress and mostly support reducing the quantity of our consumption in general, the CRAGgers seek to project a more efficient, alternative approach to sustainability (Howell, 2009). For example, CRAGgers set specific, scientifically measured goals and designate a 'carbon accountant' to calculate how much carbon emission is produced when using particular products, services and brands. By contrast, the objecteurs de croissance do not keep a numerical tally of their emissions, preferring a general reduction of their consumption practices in order to reduce their carbon emission. Additionally, locating these two groups in different geographical context offered a richer view on ideological variances. For example, the objecteurs de croissance located in France express strong cultural contestations against progress, capitalism or even American consumerism. In contrast, the CRAGgers located in the United Kingdom support progress, sustainable development, and technological innovations. Importantly, both groups of informants aimed at reducing their carbon emission and incorporated alternative and reduced consumption into their individual lifestyles.

This research is based on four types of data collection methodology: self-introspection, netnography, ethnographic and existential interviews. The study started with the use of introspection methodology. Following Gould (1991) and Holbrook’s (1995) conceptualization of introspection, the process of researcher self-introspection offered records of the researcher's conscious awareness of past experiences. The authors, although located at different places around the globe, are trying to integrate sustainability into their consumption decisions and ultimately lower their carbon emission. With the use of social media and 
conference attendances, the authors discussed their engagement and disengagement with reduced and alternative consumption practices. Particularly, one author who self-identified as an objecteur de croissance offered clear notions of identity struggles, social stigmatization, societal constrains. This author discussed several experiences when maintaining an academic carrier and lowering carbon footprint were in conflict. The second method of data collection consisted of monitoring the CRAGs' and objecteurs de croissance's blogosphere and forums, as well as reading activist works. The netnography provided insights on the similarity between the CRAGs and the objecteurs de croissance in their personal struggles to lower their carbon footprint. In order to understand the social meanings of lowering carbon footprint, the third step in data collecting was ethnography. Through personal contacts, and snow bowling techniques, one researcher was offered to spend time (one or two consecutive days) with 11 households (4 CRAGgers and 7 objecteurs de croissance). The researcher took the persona of a cultural anthropologist and lived with the informants, observing, discussing as well as participating in their daily practices. The total data collection time resulted in 171 hours spent with the CRAGgers and 200 hours spent with the objecteurs de croissance. The ethnography allowed to develop trustful relationships with informants and to gain access to personal photos and artifacts (NGO brochures, tracts, energy consumption spreadsheets, letters promoting low-carbon practices, etc.) enriched by the participants' voices. This field work helped unravel the multiple and complex meanings associated with lowering carbon footprint and the struggles associated with sustainable consumption practices. The forth step in data collection consisted of existential interviews of one to two hours with nine selfproclaimed objecteurs de croissance and nine members of the Crags' movement from various socio-professional categories aged 27 to 73 (see table 1). The interviews were performed at the place of the interviewee's residence and/or during activists'gatherings and followed the existential phenomenological process described by Thompson, Locander and Pollio (1989). 
In order to fully understand the lived experiences of individuals concerned with lowering their carbon emission, hermeneutic circle analysis (Thompson, 1997) was used to analyze the data. The method helps situate the practices of the respondents within a broader framework which includes their background (personal events, oppositions and arguments). Following Thompson's (1997) approach, the first step of the analytical procedure was to read the entire text thoroughly. This gave a sense of the entire text as it related to lowering carbon emission. Next, intratextual analysis helped identify the temporal sequencing and narrative framing of each story in relation to lowering carbon emission (Thompson, 1997). During the intertextual analysis, informants' story lines were compared and common themes emerged. In this phase, the analysis moved back and forth from the emic to the ethic interpretation, gradually providing insights in conceptualizing lived experiences of lowering carbon emission via alternative and reduced consumption. The analysis provided "the social construction of needs" and "the social imaginary" as relevant themes to individuals' experience with lowering carbon emission. The triangulation technique combining nethnography, ethnographic observations, and existential interviews confirmed and enriched each theme under the concept of the glass floor. The following discussion provides details on each theme.

\section{Findings: The Glass Floor}

No matter which practices are used (i.e.: alternative or reduced consumption), all of our data depicts personal efforts to reduce their carbon footprint. Although variably committed and devoted, our informants' testimonials converge on the difficulties and struggles to reducing carbon emission. The difficulties are diverse; including financial constraints (purchase of more expensive or rarer products), time restraints (finding 
alternatives, culinary preparations, etc.), and social struggles (risks of exclusion, need to convince one's friends or family, social embarrassment). At times, the overwhelming difficulties and the tiresome struggles create barriers to carbon reduction. In these instances, switching or reducing consumption (both oriented toward a reduction in carbon footprint) is not an option. Clear to our analysis is the existence of societal barriers that limit downward carbon emission. The carbon emission threshold under which it is almost impossible to live without clashing with dominant social norms is referred to here as the glass floor.

The notion of glass floor is adapted from the concept of glass ceiling, popularized in the 70s and 80s American feminist literature. This image of an unexpected see-through obstruction developed in context of corporate American represents the women facing the glass ceiling — a barrier that kept them from advancing past a certain point on the career ladder. Since then, the Glass ceiling has been conceptualized to designate an imaginary, yet very real, barrier that prevents women or immigrants from achieving social and professional mobility, even though it is not visible, legal or explicit (Baker \& Lightle, 2001). In the same way that a glass ceiling represents a limitation blocking upward advancement, we conceptualize a glass floor as societal constrains to lowering one's carbon footprint emission. This bottom limit is a priori invisible, but it is an inevitable barrier for those who try to switch (alternative consumption) or cut their consumption (reduced consumption). The barrier can embody structural forces, sign values or social imaginaries (Baudrillard, 1970; Castoriadis, 1987). Independent upon what a glass floor is "made of", it is a reflection of meanings that structure representations of the world in general, identify the purposes of actions and social norms and establish different types of affects that characterize the consumer society. The glass floor is the expression of the consumer society as a constraint, or moral value, imposed on consumers (Baudrillard, 1970). It is an example of the imaginary institution of society, which determines what is real and what is not (Castoriadis, 1987). The 
analysis of 18 existential interviews, ethnographic and ethnographic work offers details on the different strata that make up the glass floor to lowering carbon footprint emission.

First stratum: the social construction of needs

The glass floor is determined in relation to the definition of needs. Our analysis shows two levels of needs: the micro-individual level and the macro-individual level. The microindividual level of need occurs when our informants focus on achieving efficiency, i.e. consuming less energy and therefore reducing $\mathrm{CO}_{2}$ emissions. An illustration of this would be travelling by car as usual, but using a hybrid car. In this case, the lifestyle change is minimal. The notion of need is hardly questioned. The gain in efficiency is generally brought about by a technical or social innovation that avoids rethinking or questioning the issue of mobility. Our respondents provided many examples of efficiency: weatherproofing the home, installing a more efficient furnace. The notion of need is defined on a micro-individual level and constraining forces are negligible.

In contrast, the macro-individual level of needs takes place when informants aimed towards sufficiency via a change in lifestyle, hence a reduction of consumption and $\mathrm{CO}_{2}$ emissions. An example of this is not owning a car, even a "clean" model, and therefore organizing one's life accordingly. Here, the definition of need is operated on a macroindividual level and considerable constraining forces operate at this level. As Paulo explains: 'I don't know if you realize what it's like to work in research and refuse to fly, when everyone else is trying to get sent to international conferences!' (Paulo, 41). Paulo, like Jenny in the excerpt below, illustrates the constraining forcoes operating at a macro-social level of needs. there... But, instead I said 'Sorry, I can't go because I belong to a CRAG and I don't fly. 
Could you consider organizing videoconferences or something like that? Or maybe you should find someone locally?'... They thought I was nuts. They didn't even answer. They could have said, 'That's too bad, but we understand what you're trying to do and it's a good thing...' But they didn't even bother to answer politely. Another time they asked me to do a conference in Vienna and I said 'OK, if you book me a train ticket.' At first, they agreed, but a month later their accounting department rejected the idea so finally they asked two of my colleagues to go... Of course, they said yes and took a plane!' (Jenny, 48)

Jenny is one of our CRAGger informants. At 48 years old, Jenny struggles to incorporate green practices into her lifestyle. As Jenny explains, she belongs to a CRAG and does not want to fly. Whilst her determination to "not flying" is strongly linked to her personal values and commitment to the CRAG movement, none of her colleagues appeared to understand or even "answer politely". Jenny's workplace and colleagues consider that the normal way of life is to fly to conferences and meetings. Resistance to flying represents a deviance from the norm and is therefore penalized. By refusing to fly, Jenny suffers being stigmatized as "nuts" and excluded from participating in conferences and meetings. Clear to Jenny's excerpt is the societal need for physical mobility. Physical mobility is so embedded in individuals' routines and expectations that it is inscribed in our systems of social and cultural order (Shove, 2005). In order to participate in conference and be part of the team, Jenny is pressured to fly. Jenny's excerpt brings to mind Reisch's study on time and sustainability in which he notes that in order to be part of what he calls 'the non-stop-society' individuals are forced to adopt unsustainable lifestyles (Reisch, 2001, p. 374).

It is interesting to note that Jenny finds the strength to reject flying using her personal affiliation to a social group named the CRAG movement. Since being part of the CRAG, Jenny's determination toward reducing her carbon footprint has evolved. As she explained, 'before, I would have agreed and flown there'. Belonging to the CRAG movement changed the symbolic significance of flying. As a CRAGger, Jenny questions the normative standards of physical mobility and no longer expresses flying as a need. This example supports Slater's 
notion that needs are not absolute and mere representations of individual preferences (Slater, 1997). Jenny's need to fly has evolved along with her social interactions. As a member of the CRAG's movement, Jenny has learnt a new way of thinking about her personal consumption, lifestyles and behavior. In other words, Jenny's strength to address the normative standards of physical mobility underlines her commitment to the CRAG movement and its members. Here, incorporating green practices as a way of life does not necessarily depends upon environmental commitment but more upon social commitment.

Later in the interview, Jenny discusses a deeper and harder struggle associated with her commitment to lowering carbon emission. In the excerpt below, Jenny discusses how giving up her car created deep emotional conflicts with members of her family.

'When I decided to give up my car, my family put a lot of pressure on me...My children understood, but my brother, for example, was downright insulting. He couldn't understand; he was really harsh... When we had to meet somewhere, I told him I preferred to meet near a train station, and he would say 'why do you always need to make a fuss? I'm fed up!' Anyway, now he is more understanding, but that's because it's more mainstream.' (Jenny, 48)

In order to reduce her carbon consumption, Jenny switched from using the car to using public transportation. In her determination to use public transportation, Jenny struggles with her brother who embraces the speed and convenience of modern life and 'couldn't understand'. It is interesting to note that Jenny does not use her affiliation to the CRAGs' movement when confronted with her brother. As she mentions: "he couldn't understand." The personal level of the relationship creates intense pressures for Jenny. In the interview she hopes that, when lowering carbon emission becomes mainstream, her brother will accept her way of life. The need for social acceptance by closed relatives and friends makes lowering carbon emission particularly challenging. At times, the pressure is bearable and our informants, like Jenny above, persevere with lowering their carbon emission even if it means 
struggles and 'insults'. At other times, the social pressure is so intense that lowering carbon emission becomes impossible. As one could expect, our informants are individuals who are "concerned with others" and have strong group ties, both in terms of the consequences of their consumption and responsibility for their behavior (which can be perceived as marginal) (Moisander \& Pesonen, 2002). Thus, even if CRAGgers or objectors are very determined, they struggle to lower their carbon footprint and often 'give up' their efforts in order to 'live in peace' (Jenny).

In most cases, our informants expressed deep struggles and offered experiences of failure in their commitment to lowering carbon emission when confronted by or in conflicts with closed friends and relatives. The case of air travel for international families offers an interesting example of this phenomenon.

'When my sister announced she was marrying an American, everyone was supposed to be happy, and I was the only one who was disappointed. For me, that meant I would never see her again, because I don't want to fly...But when I said that, obviously I was the villain. They started telling me I couldn't force my lifestyle on others, etc. [...] In the end I went to see her, a few months ago, because I wasn't feeling good and I really wanted to see her. And, one night, over there, she started saying, "Anyway, thanks a lot for coming to see me. I know it was a difficult decision for you, so good for you". And I said, "No, no, don't congratulate me. I'm really not proud of what I did. For me it's really bad...I would have preferred being encouraged not to do it! " Once again, she didn't understand. For her I was just annoying.' (Juliette, 28)

In the excerpt above, Juliette expresses opposing forces. On the one hand, she does not want to fly and on the other she wants to see her sister who lives in America. Her strong commitment to low carbon emission creates tensions within her family and leads to internal struggles. For Juliette, disapprovals from family and friends are hard to accept. She does not feel 'good' being marginalized as the 'villain,' the one who is not happy when 'everyone was supposed to be happy'. Juliette's family disapproval combined with the desire to see her sister led, 'at the end', to give up reduced consumption and fly to America. This excerpt 
clearly shows the power of socially constructed needs. Although Juliette clearly expressed her refusal to fly, the general normative view around flying and visiting family members disempowered our informant. The needs to be physically mobile is socially accepted and further re-enforced by closed relatives, such as Juliette's sister, who congratulate the effort to fly and do not 'understand' its resistance. Juliette's struggles for acceptance and recognition reveal the inadequacy of autonomy and free choice in developing green marketing strategies. Juliette, like all of our informants, is not consuming alone. Our informants' consumption lifestyles are conditioned and mediated by the language of the marketplace, by social conventions and norms. Their aspiration to lower their carbon footprint has to be negotiated with socially constructed needs; needs that are nurtured by society in general and expressed by friends, family members as well as colleagues. Examples of the societal pressure to drive and/or fly were offered in all narratives. In addition to the societal expectation for mobility, our informants experienced societal struggles in the consumption of food/eating. For further details, we now cite a young objector who chose not to eat meat in order to reduce her carbon footprint.

'Often, when I ate with my mother, she would start to cry because she thought I would suffer from deficiencies. And at family dinners, there were always remarks and digs. My grandparents thought it was just a phase I was going through...In other words, they didn't understand. So, I started eating meat again, especially with them, but less than before. But recently I was in a bookstore with my mother and I was looking at a vegetarian cookbook and she said, 'Don't tell me you're a vegetarian again?' No, if you want to be left alone, it's easier to accept to eat meat.' (Kasia, 27)

For Kasia's mother and grandparents, the 'normal' and acceptable practices and ways of life include eating meat. For them, the symbolic significance of not eating meat represents suffering from deficiencies. In a country where the most revered dish, foie gras, is produced using the rather cruel tradition of goose cramming, where there is still a relatively small number of vegetarians, and where supports for animal rights is relatively weak, considering 
vegetarianism as unhealthy is indeed a common perception (Sanches 2005). In this context and faced with the familial pressure to eat meat, Kasia experiences a dilemma. Whilst she does not personally articulate a need to eat meat; she nevertheless feels obligated to fulfill such need when in the presence of her family members. As Kasia explains, the recurring 'remarks and digs' forced her to eat meat 'especially with them', her mother and grandparents. From this excerpt, we can see that green practices cannot emerge from an 'individual conceptions of subjectivity and human agency' (Autio et al., 2009, p. 42). The social construction of needs is embedded in the habitus of individuals and is carried in modes of symbolic representation. Consumption practices such as eating meat or visiting exotic places respond to needs that have become naturalized and standardized and, in the process, have gained significant symbolic representation.

Talks reflecting the problems, struggles, and even failings to practice reduced or alternative consumption were also constructed around the area of housing/heating. In the domain of in-home, private consumption practices, informants discussed constraining forces to lowering carbon emission. For example, some of our informants complained about the French government imposing regulations on house heating. In France, the law on construction and habitation, code $n^{\circ} 69-256$ developed on June $14^{\text {th }} 1969$ demands inhabitants to incorporate heating facilities capable of maintaining the house at 18 degrees Celsius. For our informants who attempt to re-evaluate these needs to lower their carbon footprint, they face legal penalties. Along heating the home, legal requirement exists around the construction of private properties. For example, one cannot insure a home built from straws.

Our analysis shows that by lowering carbon emission, our informants separate from our embedded societal norms of cleanliness (some objecteurs de croissance and CRAGgers 
wash quickly with cold water), of warmth and comfort (they use little heating), of mobility and speed (they travel on foot or by bike), and of freedom and choice (they refuse to travel by air). These societal norms confirm that we do not consume alone and that our needs for consumption are socially constructed and hence hard to re-negotiate alone. In all the examples presented here, the individual must deal with external pressures against reduced carbon consumption. Those who manage to continually and systematically reduce their carbon emission to a minimum risk being called out in various ways, from disapproval to conflict and marginalization. In all cases, the social cost can be very high: permanent deterioration of family ties, professional disqualification, or social marginalization. Faced with societal disapproval, individuals are forced to either, reconsider their goals and lower their standards, for example by accepting to fly or eat meat, or to "stand firm" and endure the consequences.

In the following discussion, we further explain the glass floor to low carbon emission offering the second stratum entitled the social imaginary.

\section{Second stratum: the social imaginary}

In this manuscript, the notion of social imaginary refers to Castoriadis' conceptualization of 'l'imaginaire social' (Castoriadis, 1987). For Castoriadis, the social imaginary represents the social world as a mediating collective life evolving along historical times. The social imaginary is made of first-person subjectivities that build upon implicit understandings that make possible common practices (Gaonkar, 2002).These implicit understanding are created and maintained by diverse institutions such as the laws or the media (Castoriadis, 1987). As such, the social imaginary is similar to a "collective picture", which provides the means by which we understand our identities and our place in the world (Bouchet, 1994, p. 407). Castoriadis (1987) suggests the existence of different layers of the social imaginary: the 
external level imposed by the internal level which transforms "psychic monads" into socialized individuals, the intrinsic level that represents individuals' need for coherence within the symbolic order, the natural and material environment, and the historical level and its reproductive inertia (Castoriadis, 1987). Each level, as we will discuss, is represented in our data.

The analysis of our informants' personal experience in lowering carbon emissions and the individual meanings they affiliate to alternative or reduced consumption unveils the four layers of the social imaginary presented by Castoriadis (1987). For example, in the excerpt below Audrey describes her sustainable practices along the line of social imaginary.

I have made efforts in many areas. I gave up my car, for example, and that was a big deal...But never taking a plane is very difficult, because I need it to get away from it all and see the world...I allow myself a flight once in a while.' (Audrey, 27)

Audrey, a 27 self-defined 'objecteur de croissance' who works for an environmental nonfor-profit organization, aims at resisting progress and reducing her $\mathrm{CO}_{2}$ emissions to a bare minimum. Whilst strongly committed to the preservation of the natural environment within both her personal and professional spheres, Audrey admits that she enjoys seeing "the world" and flying to exotic places. Situated within the social imaginary, the practice of flying engorges with symbolic representation. For Audrey, flying, unlike driving a car, represents a means 'to get away'. It symbolizes an escape, a freedom to discover faraway places. Here, the symbolic representation of flying draws on a logic implicit to Audrey's social world and therefore cannot be reduced to a notion of rationality or reality. Rather, it responds to what Castoriadis calls 'la logique ensembliste-identitaire,' a co-belonging of identification (Thompson, 1982). For Audrey, flying symbolizes being part in the social world, it represents a co-belonging or a holding-together as socialized individuals, the first layer of the social 
imaginary. Audrey, who again is extremely committed to reducing her carbon emission, accepts unsustainable practices as part of their daily life, or more precisely, as part of her identity. Later in her narrative, she explains that she 'wouldn't be the same if she gave up flying completely." Here, reduced consumption is constrained by a need for coherence within the symbolic order, the second layer of the social imaginary.

Our field-work supports that alternative and reduced consumption practices are also constrained at the material level of the social imaginary. The CRAGgers and the objecteurs de croissance often faced external difficulties when trying to reduce $\mathrm{CO}_{2}$ emissions. For example, many of our informants' cannot find local food in a large city like Paris or London. Similarly, permaculture gardening requires land space, which some of our informants did not have access to (see figure $1 \& 2$ ). In rural areas, the issue of transportation is more prominent, as it is difficult to do without a car in areas where public transport is non-existent or not highly developed.

Finally, all of our informants faced constrained forces linked to the history and reproductive inertia level of the social imaginary. This constraining forth level of the social imaginary is exemplified in the following excerpt:

'My car runs on used cooking oil... Of course, that's illegal, but it's no big deal! I'm not hurting anyone, on the contrary, so I don't see why I shouldn't.' (William, 52)

William, a 52 years old CRAGger, is strongly committed to reducing his carbon emission. Toward this aim, William has developed several creative products that consume less energy, one of which is a car that runs on cooking oil. Whilst William is proud of his personal 
invention, he cannot communicate or share it with anyone as the product is 'illegal'.

Similarly, in the area of eco-friendly architecture, one objecteur de croissance explained the loopholes he used to get around the historical inertia of rules and regulations in the insurance business:

'If you want to insure a straw house, most insurers refuse because they think that straw is an obvious fire hazard...It's stupid because compressed straw is less flammable than polystyrene, for example, but that's the way it is; they won't hear of it. So, I declared I had cellulose insulation. Technically, this is true because straw is a type of cellulose, but since it sounds more technical it's more easily accepted.' (Martin, 43)

These illustrations show that, in their desire to reduce carbon emissions, our informants were confronted to the four different layers of the social imaginary described by Castoriadis (1987). Whilst these four layers of the social imaginary were most explicit in discussions of mobility and food consumption (perhaps due to their public consumption spaces), the social imaginary also played its role in the domain of house/heating consumption. For example, our informants' narratives offered representations of the social imaginary on domestic consumption and the ways in which consumer goods were used in the everyday life of the home when discussing issues of hospitality. For example, the ethnographic work reveals that, whilst all of our informants - whether CRAGgers or objecteurs de croissance - were most welcoming, they were also quite reluctant to invite the researcher to spend the night at their private home. One the one hand, our informants were willing to open their home and share their strong set of beliefs and values regarding carbon emissions. On the other hand, they were also required to respond to the societal norms of hospitality including providing comfort to guests. When the researcher was offered and ultimately spent the night, most informants repeatedly offered apologies and excuses for hosting the researcher without adequate heating, hot water and comfort. These attempts to excuse their lower carbon consumption reveal the logic of the social imaginary and the powerful representations - "the collective picture" we 
have of society imaginary, which operates as a fundamental principle within society (Bouchet, 1994, p. 407).

The recognition of constraining forces to alternative and reduced consumption, gives us the capacity to think of sustainability outside of prescribed practices dictated by technical rationality or idealist philosophy. In all narratives, our informants' desire to lower their carbon emission does not fully respond to a prescribed idealist philosophy on how to live life nor does it fully respond to the technological rationality of eco-efficiency and/or sufficiency. Rather, our informants' reduced and alternative consumption practices primarily respond to practicality and are expressed through the medium of symbolic representation. As such, their practices are neither indifferent to nor wholly fixed by technological rationality. At the same times, these practices are neither accidental nor fully prescribed by idealistic philosophy. They are practical and symbolic. When reduced or alternative consumption are not practical, our informants opt for unsustainable options that they symbolically interpret as essential needs. These unsustainable options are situated within the social imaginary, which helps informants understand their identity and place in the world. The rationale observed here is very interesting and demonstrates that an unacceptable means of consumption in terms of the logic of sustainability is expressed as an acceptable need. How does an unsustainable practice become an acceptable need to our informants? If we follow the reasoning of Shove (2003) on the social construction of consumption standards, we can suppose that this subjective need, which appears to reflect individual preferences, corresponds to a social norm that contributes to determining the individual's preferences. Taking a trip to a faraway place (therefore by plane) offers the perfect illustration of an 'unsustainable' consumption standard that has been accepted and internalized by the interviewees as a necessary need. As Juliette explains below, flying, even for a vacation is 'the way it is'. 
'I know, I shouldn't have gone, especially since it was just for a vacation...I'm not proud of myself, but that's the way it is.'(Juliette, 28)

Juliette is a 28 years old woman who identifies as an 'objecteur de croissance.' Earlier in her narrative, Juliette expressed a firm resistance to flying. For Juliette, flying is particularly detrimental to the natural environment. Although well rooted in her knowledge, the environmental impact of flying does not stop Juliette from flying. As presented earlier in the manuscript, Juliette flew to North America to visit her sister and as she explains above, she also flies to go on vacation. Clear to this example is the notion that unacceptable consumption practices become internalized as essential needs. Furthermore, this excerpt challenges the modernist axiom of rationality and free choices when adopting sustainable practices. Above, Juliette explains that she is 'not proud' of herself and yet she flies because 'that's the way it is'. Here, Juliette is aware that flying is not sustainable and yet she flies. Her knowledge of the impact of flying on the environment does not lead to consequent action. In green marketing literature, this finding is not new. Many authors have discussed that knowledge does not translate to more sustainable consumption practices (Schaefer \& Crane, 2005; Thogersen, 2005). From our analysis, this knowledge-action gap may be due to the idea that consumers do not always have the choice to convey their knowledge into action. As Juliette explains, 'she shouldn't have gone'. Situated within the social imaginary, flying is for Juliette, an internalized need that has to be satisfied. Consequently, Juliette's knowledge on environmental degradation is not absolute and definite. According to Castoriadis (1987), any action, including practicing reduced or alternative consumption, stands in relation to a knowledge that is fragmented and provisional. 'It is fragmented because there can be no exhaustive theory of humanity and of history; it is provisional because praxis itself constantly gives rise to new knowledge for it makes the world a language that is at once singular and universal' (Castoriadis, 1987, p. 77). Thus, sustainable practices do not emerge from an 
absolute knowledge on environmental degradation leading to rational practices but rather from provisional knowledge that is adapted to individuals' first-person subjectivities and situated within the social imaginary.

To speak of fragmented and provisional knowledge is to raise again the ambiguity surrounding the definition of sustainability and its distinction from unsustainable practices (Black \& Cherrier, 2010). Our analysis supports that sustainable consumption practices are situated within the social imaginary outside binary oppositions between right and wrong or, more particularly, between sustainable and un-sustainable (Thompson, 1982). For our respondents, the dominant standard of consumption is a powerful source of temptation, even though it is often incompatible with their goal of sustainability. This incompatibility is accepted because it is part of the social imaginary. For example, most of our informants accept the norms of mobility and communication as a need. Our field-work reveals that both CRAGgers and objecteurs de croissance own a computer and none of the narratives questioned the ownership and use of a computer even though it does consume energy. As such, alternative or reduced consumption cannot be reduced to a structure of oppositions between sustainable versus un-sustainable, rather it refers to 'a meaning that can never be given independently of every sign but which is something other than the opposition of signs, and which is not unavoidably related to any particular signifying structure [...]' (Castoriadis, 1987, p.137). The recognition of alternative and reduced consumption outside of oppositional structure gives us the capacity to think of sustainability outside of prescribed practices.

\section{Conclusion}

Using the case of CRAGgers and objecteurs de croissance, we have tried to demonstrate the limits of reducing carbon emission as well as the constraining forces to sustainable 
practices. Clear to our analysis is that, today, alternative and reduced consumption remains a preoccupation limited to individual circles and a terra incognita for the collective social sphere.

Our analysis shows the existence of socio-cultural barriers to downward carbon emission. These barriers, that we combined under the concept of the glass floor, represents external as well as internalized socio-cultural standards preventing our informants from achieving their goal of reducing carbon footprint to a bare minimum. With the risk of oversimplification, we can broadly perceive that external social standards are mostly linked to the social construction of needs and that internal social standards are mainly connected to the social imaginary.

The analysis identifies limits to reducing carbon emission in terms of socially constructed needs. Our informants do not have the autonomy to identify "true" versus "false" needs nor do they have the capacity to satisfy the "true" ones. Needs are relational, they are embedded in social relations and therefore cannot be re-evaluated at the individual level. When the interviewees do find the necessary willpower and self-confidence to reassess their needs and free themselves from external social standards, family and friends incarnate the dominant social norm and try to bring them back into the fold. What we have is something akin to a humanity's collective unconscious (Campbell, 1991) where individuals unconsciously adhere to socially constructed needs. This findings stands in sharp contrast with commentators arguing that carbon emission is "the one thing you have direct control over - your carbon footprint" and that "our future is in our own hands" (Siegel 2007).

In this respect, green marketing, the discipline of markets and marketers, builders of norms, has an important role to play. First, we suggest that green marketing approaches alternative and reduced consumption as social practices instead of individual choices 
performed by autonomous agents. Importantly, social practices are to be considered embedded in power relationships (Shove, 2005; Thogersen, 2005; Wilhite \& Lutzenhiser, 1998). Such consideration necessitates understanding how power relationships operate in the domain of sustainable practices and shift through individuals and institutions. According to Kilbourne, McDonald and Prothero's (1997), considering power relationships when promoting sustainable consumption calls for a paradigm shift. For Kilbourne et al. (1997), reframing consumption from a focus on acquisition to ways of living sustainably demands shifting away from the dominant social paradigm to integrate a 'new environmental paradigm" (Kilbourne, 1998). From policy initiatives, to educational program and the development of collaborative consumption support, the new environmental paradigm reflects a downstream approach to change and demands green marketers to work in close collaboration with structural powers. Second, our analysis points out that one big challenge in green marketing is to de-normalize needs for consumption beyond necessities and to normalize practices of conservation, sharing, reusing, recycling, slowing down, treasuring, and downshifting consumption. For Verplanken and Wood (2006), strategies aimed at countering the social and cultural barriers to downward consumption need to include an upstream approach that focuses on the individual desire for material acquisition. In this view, green marketing needs to embrace both a downstream as well as an upstream approach to societal change. This appears feasible via what Polonsky (2011) names transformative green marketing, which tackles simultaneously the inability of consumers, firms and governments to integrate a macro-marketing perspective into their respective micro-decisions. Additionally, the glass floor is maintained and reinforced by the social imaginary. According to Castoriadis (1987), the social imaginary is necessary for society to articulate its identity and its relation to the world as it "contains a specific understanding of what human beings are to do in this world (Bouchet 1994, p. 420). To say that our informants' downward 
consumption faced the social imaginary is, thus, to indicate the power of institutions creating, supporting and maintaining social and cultural barriers to lowering carbon footprint. As Castoriadis (1987) explains, the social imaginary is reinforced by institutions. These institutions are diverse. For example, money is an institution, that is, a collective tool organizing societies and its people (Bouchet 1994). Researchers have identified diverse institutions maintaining the social imaginary including rituals, customs, festivals, ceremonies, norms, the media, or even magic that inscribe individuals to cultural traditions (Arnould, Price, \& Otnes 1999; Baudrillard, 1997). Whilst our aim was not to specifically identify the institutions maintaining our informants' social imaginary, we argue, based on our data, that the media play a central role in maintaining consumption as the dominant norm and in marginalizing downward consumption. For example, currently when sufficiency is covered in the media, the images or examples provided are often caricatures that highlight the exotic, even strange, aspects of these practices. Individuals who concentrate on reducing their carbon emission such as the CRAGgers or the Objecteurs de Croissance are sometimes referred to as “Carborexics" by moral entrepreneurs (Becker, 1963). In addition to the media, our study identifies academia as a powerful institution maintaining the social imaginary. For example, Shaw and Riach (2011) note that downshifters, voluntary simplifiers, or even ethical consumers are often studied along notion of consumer resistance, rebellion or countercultural movement. This, we believe, may have the powerful force to replicate our representations of voluntary simplicity as tree-huggers and downshifters as deviant and marginal individuals. To say that academia participate in reproducing the glass floor to downward consumption is, thus, a call for green marketing researchers to de-marginalize discussions on green practices.

The glass floor reflects the heteronomy of consumer societies where the notion of need is untouchable. Consumption practices have gradually become naturalized and 
standardized and are therefore non-negotiable even though they are unsustainable (Shove, 2003). This emphasizes that we do not consume energy alone. The implication for green marketers is to understand consumption 'as a set of energy use behaviours deeply rooted in the social, cultural and symbolic presentation of the home' (Wilhite, Nakagami, Masuda, Yamaga \& Haneda, 2001, p.166). As energy use behaviours, consumption practices provide energy services including comfort, cleanliness, or speed, that have an essential meaning within the social imaginary (Wilhite \& Lutzenhiser, 1998). Such findings orient green practices close to tactics defined by de Certeau (1980). Tactics express a commitment to daily resistance, characterized by the immediacy of a struggle and the urgency of random actions. To change energy consumption habits, governments and NGOs have been devoting significant means to education, communication and raising awareness among individuals, based on the principle that only the will was lacking (or what researchers refer to as 'attitude'). However, our research shows that an individual, although aware and highly motivated, must have a high capacity for resistance and even a willingness to make sacrifices, to bear the social cost of transgressing the collective consumption norms conveyed by the social imaginary. The changes our modern-day challenges require (global warming, limited resources, etc.) in terms of consumption should be the result of a strategy (e.g.de Certeau, 1980). It must consist in a quasi-methodical construction of a new balance of powers capable of producing a change in the social imaginary. This, we argue, is in part the role of green marketers. 
Table 1 : Informants

\begin{tabular}{|c|c|c|c|c|c|}
\hline Pseudonym & Group affiliation & Age & Gender & Family status & Occupation \\
\hline Martin & Objecteur de croissance & 43 & Male & $\begin{array}{l}\text { Married, } 4 \\
\text { children }\end{array}$ & Architect \\
\hline Kasia & Objecteur de croissance & 27 & Female & $\begin{array}{l}\text { A partner, no } \\
\text { child }\end{array}$ & Student \\
\hline Juliette & Objecteur de croissance & 28 & Female & $\begin{array}{l}\text { A partner, no } \\
\text { child }\end{array}$ & Journalist \\
\hline Violette & Objecteur de croissance & 32 & Female & $\begin{array}{l}\text { Married, no } \\
\text { child }\end{array}$ & University Professor \\
\hline Paulo & Objecteur de croissance & 41 & Male & $\begin{array}{l}\text { Married, } 2 \\
\text { children }\end{array}$ & University Professor \\
\hline Corentin & Objecteur de croissance & 31 & Male & $\begin{array}{l}\text { A partner, } 1 \\
\text { child }\end{array}$ & $\begin{array}{l}\text { Unemployed } \\
(« \text { working objector } »)\end{array}$ \\
\hline Alice & Objecteur de croissance & 29 & Female & $\begin{array}{l}\text { A partner, } 1 \\
\text { child }\end{array}$ & $\begin{array}{l}\text { Unemployed } \\
(« \text { working objector } »)\end{array}$ \\
\hline Audrey & Objecteur de croissance & 27 & Female & $\begin{array}{l}\text { Single, no } \\
\text { child }\end{array}$ & $\begin{array}{l}\text { Employed } \\
\text { environmental NGO }\end{array}$ \\
\hline Annie & Objecteur de croissance & 49 & Female & $\begin{array}{l}\text { A partner, no } \\
\text { child }\end{array}$ & Language teacher \\
\hline Jenny & Cragger & 48 & Female & $\begin{array}{l}\text { Married, } 4 \\
\text { children }\end{array}$ & Doctor \\
\hline Alistair & Cragger & 55 & Male & $\begin{array}{l}\text { Married, } 2 \\
\text { children }\end{array}$ & Consultant \\
\hline Jane & Cragger & 29 & Female & $\begin{array}{l}\text { Single, no } \\
\text { child }\end{array}$ & $\begin{array}{l}\text { Project manager on } \\
\text { energy }\end{array}$ \\
\hline Tim & Cragger & 49 & Male & $\begin{array}{l}\text { Single, no } \\
\text { child }\end{array}$ & $\begin{array}{l}\text { Employed } \\
\text { environmental NGO }\end{array}$ \\
\hline Simon & Cragger & 60 & Male & $\begin{array}{l}\text { Married, } 1 \\
\text { child }\end{array}$ & retired (bookseller) \\
\hline Peter & Cragger & 73 & Male & $\begin{array}{l}\text { Married, } 2 \\
\text { children }\end{array}$ & retired (fireman) \\
\hline Philip & Cragger & 54 & Male & $\begin{array}{l}\text { Married, } 2 \\
\text { children }\end{array}$ & Green energy retailer \\
\hline Ismael & Cragger & 48 & Male & $\begin{array}{l}\text { A partner, no } \\
\text { child }\end{array}$ & Builder \\
\hline William & Cragger & 52 & Male & Single, 1 child & Farmer \\
\hline
\end{tabular}


Figure 1: Permaculture Gardening

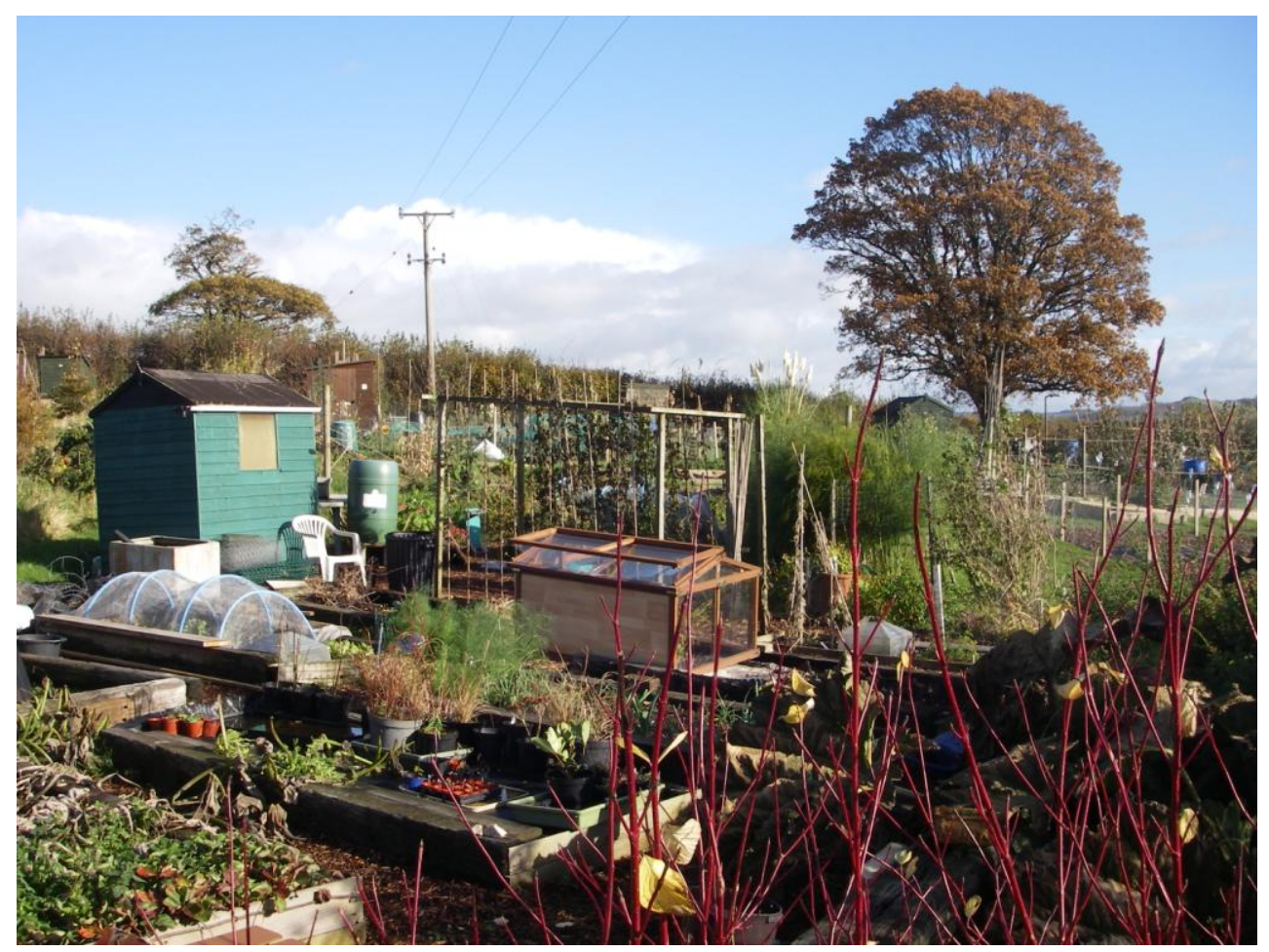

Figure 2: Man-made Chicken Coop

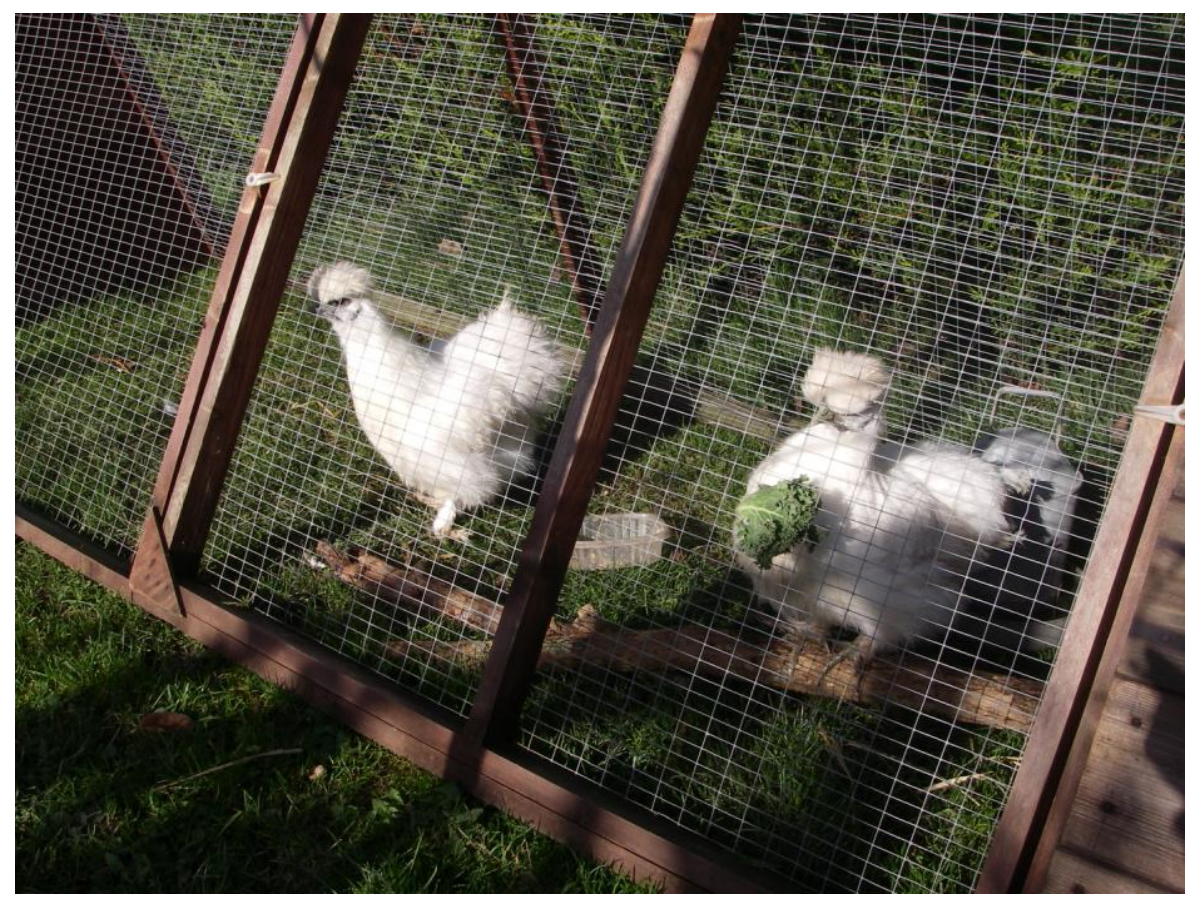




\section{References}

Arnould, E. J., Price, L. L., \& Otnes, C. (1999). Making Consumption Magic: A Study of White Water River Rafting. Journal of Contemporary Ethnography, 28, 33-68.

Arrow, K., Dasgupta, P., Goulder, L., Daily, G., Ehrlich, P., Heal, G., \& Walker, B. (2004). Are we consuming too much?. Journal of Economic Perspectives, 18 (3), 147-172.

Autio, M., Heiskanen, E., \& Heinonen, V. (2009). Narratives of 'green' consumers - the antihero, the environmental hero and the anarchist. Journal of Consumer Behaviour, $8,40-53$.

Baker, B., \& Lightle, S.S. (2001). Cracks in the glass ceiling: An analysis of gender equity in the federal government auditing career field. The Journal of Government Financial Management, 50 (3), 18-26.

Baudrillard, J. (1997/1970). Consumer Society : Myths and Structures (Theory, Culture and Society). Sage Publications, London.

Becker, H.S. (1963). Outsiders: studies in the Sociology of Deviance. The Free Press, New York, NY.

Belz, F.M., \& Peattie, K. (2009). Sustainability marketing, a global perspective. London, UK: John Wiley.

Black, I., \& Cherrier, H. (2010). Anti-consumption as part of living a sustainable lifestyle: daily practices, contextual motivations and subjective values. Journal of Consumer Behaviour, 9, 437-453.

Borgmann, A. (2000). The moral complexion of consumption. Journal of Consumer Research, 26, 418-422.

Bouchet, D. (1994) 'Rails without Tics: The Social Imaginary and Postmodern Culture. Can Postmodern Consumption Replace Modern Questioning?', International,journal of Research in Marketing 11: 405-22.

Boutaud, A., \& Gondran, N. (2009). L'empreinte écologique. Paris: La Découverte, Collection Repères.

Brundtland Report. (1987). Our common future, Oxford: Oxford University Press.

Campbell, J. (1991). The power of myth. New York, NY: Anchor Books.

Castoriadis, C. (1987). The imaginary institution of society. Cambridge: Polity Press.

Cherrier, H., \& Murray, J. B. (2007). Reflexive dispossession and the self: constructing a processual theory of identity. Consumption, Markets \& Culture, 10, 1-30.

Connolly, J. (2003). Sustainable consumption, consumption, consumers and the commodity discourse. Consumption, Markets \& Culture, 6, 275-291.

Dahlstrom, R. (2011). Green makreting management. Mason, OH: South-Western Cengage Learning.

De Certeau, M. (1980). L'invention du quotidien : Arts de faire (volume 1). Paris, Folio.

Dolan, P. (2002). The sustainability of "sustainable consumption". Journal of Macromarketing, 22, 170-181.

Durning, A. (1992). How Much is Enough? The consumer society and the Future of the Earth. New York: Norton

Elgin, D. (1981). Voluntary simplicity : Toward a way of life that is outwardly simple, inwardly rich. New York, NY: Morrow.

Elkington, J., Hailes, J., \& Makower, J. (1990). The green consumer. New York, NY: Penguin Books.

Fisk, G. (1973). Criteria for a theory of responsible consumption. Journal of Marketing, 37(2), 24-31. 
Fuchs, D.A., \& Lorek, S. (2005). Sustainable consumption governance: a history of promises and failures. Journal of Consumer Policy, 28, 261-288.

Gaonkar, D.P. (2002). Toward new imaginaries: an introduction. Public Culture, 14, 1-19.

Gould, S. J. (1991). The Self-Manipulation of My Pervasive, Perceived Vital Energy through Product Use: An Introspective-Praxis Perspective. Journal of Consumer research, 18:September, 194-207.

Grant, J. (2007). The green marketing manifesto. Chichester, West Sussex, UK: John Wiley \& Sons, Inc.

Heiskanen, E. (2005). The performative nature of consumer research: consumers' environmental awareness as an example. Journal of Consumer Policy, 28, 179-201.

Heiskanen, E., \& Pantzar, M. (1997). Toward sustainable consumption: two new perspectives. Journal of Consumer Policy, 20, 409-442.

Hobson, K. (2002). Competing discourses of sustainable consumption: does the rationalisation of lifestyles make sense? Environmental Politics, 11, 95-120.

Holbrook, M. B. (1995). Consumer research: introspective essays on the study of consumption. Thousand Oaks, CA: Sage.

Howell, R. (2009). The experience of carbon rationing action groups: implications for a personal carbon allowances policy. UKERC report.

Iyer, R., \& Muncy, J. A. (2009).The Purpose and object of anti-consumption. Journal of Business Research, 62, 160-168.

Kilbourne, W.E. (1998). Green marketing: a theoretical perspective. Journal of Marketing Management, 14, 641-655.

Kilbourne, W., \& Beckmann, S. (1998). Review and critical assessment of research on marketing and the environment. Journal of Marketing Management, 14, 513-32.

Kilbourne, W.E., McDonald, P. \& Prothero, A. (1997). Sustainable consumption and the quality of life: a macromarketing challenge to the dominant social paradigm. Journal of Macromarketing, 17, 4-23.

Latouche, S. (2005). Décoloniser l'imaginaire. Lyon: Parangon.

Moisander, J. \& Pesonen, S. (2002). Narratives of sustainable ways of living: consructing the self and the other as a green consumer. Management Decision, 40, 329-342.

Nava, M. (1991). Consumerism reconsidered: buying and power. Cultural Studies, 5, 157173.

Ottman, J.A. (1993). Green marketing: Challenges and opportunities. Lincolnwood, IL: NTC Business Books.

Ottman, J.A. (2011). The New rule of green marketing: strategies, tools, and inspiration for sustainable branding. San Francisco, CA: Berrett-Koehler Publisher, Inc.

Polonsky, M. J. (2011). Transformative green marketing: Impediments and opportunities Journal of Business Research, In press.

Pierce, L.B. (2000). Choosing simplicity, real people finding peace and fulfillment in a complex world. Carmel, Ca: Gallagher Press.

Reisch, L.A. (2001). Time and wealth: the role of time and temporalities for sustainable patterns of consumption. Time \& Society, 10, 367-385.

Sanches, S. (2005). Sustainable consumption à la française? Conventional, innovative, and alternative approaches to sustainability and consumption in France. Sustainability: Science, Practice, \& Policy, 1, 43-57

Sand1kc1, Ö., \& Ekici, A. (2009). Politically Motivated Brand Rejection. Journal of Business Research, 62(2), 208-217.

Sanne, C. (2000). Dealing with environmental saving in a dynamic economy: how to stop chasing our tail in the pursuit of sustainability. Energy Policy, 28, 487-495. 
Schaefer, A., \& Crane, A. (2005). Addressing sustainability and consumption. Journal of Macromarketing, 25, 76-92.

Schor, J. (1998). The overspent American : Upscaling, downshifting, and the new consumer. New York, NY: Basic Books.

Schor, J. (1999). The overspent American: Why we want what we don't need. New York, NY: HarperPerennial.

Schor, J. (2000). Toward a new politics of consumption. In J.B.S. \& D.B. Holt (Eds.), The consumer society reader (446-462). New York, NY: The New Press.

Schumacher, E.F. (1974). Small is beautiful : A study of economics as if people mattered. London, UK: Sphere Books.

Shaw, D., \& Riach, K. (2011). Embracing ethical fields: constructing consumption in the margins. European Journal of Marketing, 45(7/8), In press

Shaw, D., Newholm, T. \& Dickinson, R. (2006). Consumption as voting: an exploration of consumer empowerment. European Journal of Marketing, 40, 1049-1067.

Shove, E. (2003). Comfort, cleanliness and convenience: the social organization of normality. Berg, Oxford, New York, NY.

Shove, E. (2005). Changing human behaviour and lifestyle: a challenge for sustainable consumption?. In I. Ropke \& L. Reisch (Eds.), Consumption - perspectives from ecological economics (111-132). Cheltenham: Elgar.

Siegel, L. (2007). The Low-Carbon Diet, Observer Magazine 21/1/07. http://www.guardian.co.uk/environment/2007/jan/21/observermagazine.ethicalliving Accessed on line: 27/06/2011.

Slater, D. (1997). Consumer culture and the politics of needs. In M. Nava, A. Blake, I. MaRury \& B. Richards (Eds.), Buy this book (51-63). London, UK: Routledge.

Tanner, C., \& Kast, S.W. (2003). Promoting sustainable consumption: determinants of green purchases by swiss consumers. Psychology \& Marketing, 20, 883-903.

Thogersen, J. (2005). How may consumer policy empower consumers for sustainable lifestyles?. Journal of Consumer Policy, 28, 143-178.

Thompson, J.B. (1982). Ideology and the social imaginary: an appraisal of Castoriadis and Lefort. Theory and Society, 11, 659-681.

Thompson, C.J. (1997). Interpreting consumers: A hermeneutical framework for deriving marketing insights from the texts of consumers' consumption stories. Journal of Marketing Research, 34 (4), 438-456.

Thompson, C. J., Locander, W. B., \& Pollio, H. R. (1989). Putting Consumer Experience back into Consumer Research: The Philosophy and Method of ExistentialPhenomenology. Journal of Consumer Research, 16(4), 133-147.

Verplanken, B., and Wood, W. (2006). Interventions to break and create consumer habits. Journal of Public Policy \& Marketing, 25(1), 90-103.

Wilhite, H., \& Lutzenhiser, L. (1998). Social loading and sustainable consumption. Advances in Consumer Research, 26, in Arnould E.J. \& Scott L.M.(pp. 281-287), Association for Consumer Research, Provo, UT.

Wilhite, H., H. Nakagami, T. Masuda, Y. Yamaga, \& H. Haneda. (2001). A cross-cultural analysis of household energy-use behavior in Japan and Norway. in D. Miller (ed), Consumption: Critical Concepts in the Social Sciences, Vol 4 (pp.159-177). London and New York: Routledge. 